\title{
Tinjauan Ulang Rekonstruksi Lempeng Laut Filipina
}

\author{
Lina Handayani*
}

\begin{abstract}
Lina Handayani, Tinjauan Ulang Rekonstruksi Lempeng Laut Filipina, RISET - Geologi dan Pertambangan Jilid 16 No 1. Tahun 2006, halaman 24 - 29. 5 gambar

Sari: Proses terbentuknya lempeng Laut Filipina sebenarnya cukup dapat dimengerti dengan adanya beberapa sistem punggungan dan palung yang telah diketahui umurnya. Yang menjadi permasalahan adalah adanya beberapa pendapat tentang perubahan posisi lempeng ini sejak terbentuk (sekitar 50 juta tahun yang lalu) hingga posisinya saat ini. Tomografi dari data seismik yang dapat memetakan lempeng-lempeng yang terkubur di dalam mantel menunjukkan bahwa posisi lempeng tidak banyak berubah sejak saat lempeng ini terbentuk.
\end{abstract}

\section{PENDAHULUAN}

Evolusi tektonik daerah Pasifik bagian barat, termasuk Lempeng Laut Filipina, sangatlah kompleks. Lempeng Laut Filipina dibatasi di semua sisinya oleh batas konvergensi, dan merupakan komponen kunci dari rekonstruksi daerah Pasifik Barat (Gambar 1).



Gambar 1. Fitur tektonik utama Pasifik Barat. (CBSC = Central Basin Spreading Center). Sumber data untuk peta topografi: Smith \& Sandwell, 1997.

*Pusat Penelitian Geoteknologi - LIPI
Penelitian-penelitian terdahulu telah menghasilkan beberapa konsep rekonstruksi Lempeng Laut Filipina. Pembentukan bagianbagian lempeng telah dipahami melalui data yang diambil dari laut maupun pulau-pulau kecil di dalam wilayah lempeng. Namun evolusi lempeng secara keseluruhan masih diperdebatkan karena data-data yang mendukung masih sangat kurang. Pemodelan tomografi yang mampu menampilkan kondisi bawah permukaan, dapat memberikan masukan baru bagi pemahaman tektonik daerah ini.

\section{Teori rekonstruksi terdahulu}

Ada beberapa teori rekonstruksi yang dapat dikategorikan menjadi 2 kelompok. Pertama adalah yang mengemukakan bahwa Lempeng Laut Filipina bergerak dari ekuator sampai di lokasinya sekarang dengan berotasi hampir sebesar 90 sejak Miosen (Hall, 2002; Deschamps, 2001). Kelompok kedua mengemukakan bahwa Lempeng Laut Filipina bergerak ke arah utara dengan sedikit rotasi se arah jarum jam (Seno \& Maruyama, 1984; Hilde et al., 1977; Uyeda et al., 1972).

Hall (2002) menyusun suatu rekonstruksi yang sangat menarik berdasarkan data paleomagnet yang diperoleh dari berbagai sumber. Gambar 2 diambil dari rekonstruksi Hall (2002), yang menggambarkan evolusi daerah Pasifik Barat. Tampak bahwa zona subduksi IzuBonin semula (50 Ma) berarah hampir BaratTimur dan berada di sekitar khatulistiwa. Dalam evolusinya lempeng tersebut mengalami rotasi 


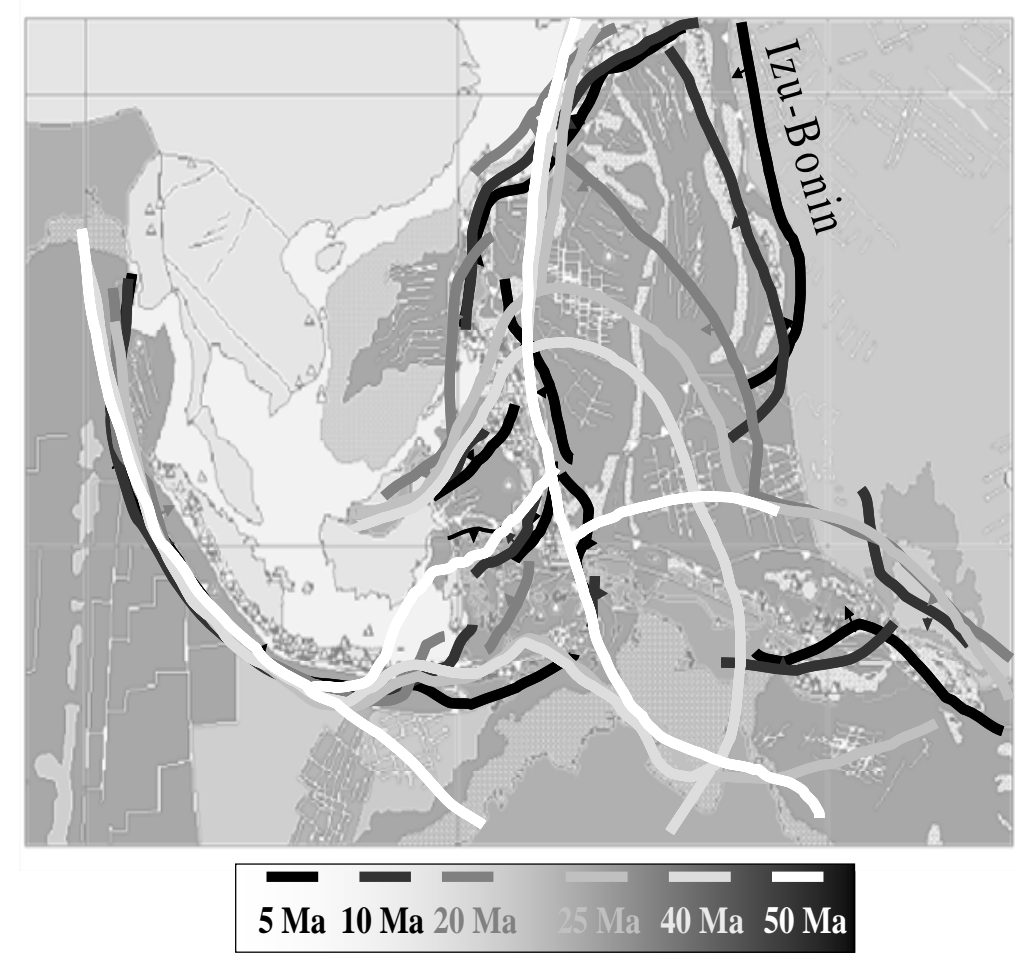

Gambar 2. Pergeseran zona subduksi selama 50 juta tahun terakhir menurut Hall, modifikasi dari Hall, 2002). Perhatikan batas lempeng timur laut (zona subduksi Izu-Bonin).

sehingga menempati posisi yang sekarang di sekitar $20^{\circ}-35^{\circ} \mathrm{LU}$ dengan arah Utara-Selatan.

Data yang digunakan untuk membuktikan adanya rotasi Lempeng Laut Filipina adalah data paleomagnet yang diperoleh dari Pulau Halmahera dan beberapa pulau di wilayah Lempeng Laut Filipina (Hall, 1995). Data yang digunakan ini sesungguhnya memiliki beberapa kelemahan. Salah satunya yaitu karena data paleomagnet yang diambil dari beberapa pulau di dalam wilayah lempeng Laut Filipina menunjukkan pergerakan dan perputaran yang berbeda (Haston \& Fuller, 1991; McCabe 1987). Hal tersebut menunjukan kemungkinan yang lebih besar bahwa pergerakan yang terekam adalah pergerakan individual masing-masing pulau tersebut, dan bukan pergerakan total dari lempeng itu sendiri.

\section{MODEL TOMOGRAFI}

Model tomografi merupakan hasil inverse dari data gempabumi tercatat. Untuk keperluan studi ini, digunakan hasil pemodelan dari Widiyantoro (1997). Pemodelan menggunakan data gelombang $\mathrm{P}$ dan $\mathrm{S}$ dari data gempabumi tercatat yang telah di lacak ulang (retrace).

Dalam pemodelan, mantel bumi dibagi menjadi beberapa lapisan, masing-masing untuk model gelombang $\mathrm{P}$ dan S. Anomali kecepatan positif menunjukkan bagian mantel yang relatif lebih dingin, atau diinterpretasikan sebagai lempeng yang tersubduksi. Gambar 3 merupakan hasil interpretasi gabungan dari model gelombang P dan S (Handayani, 2004). Dalam tulisan ini hanya ditampilkan beberapa lapisan teratas saja yang dianggap dapat menampilkan keadaan lempeng tersubduksi dalam kurun waktu evolusi lempeng yang akan dibahas. 

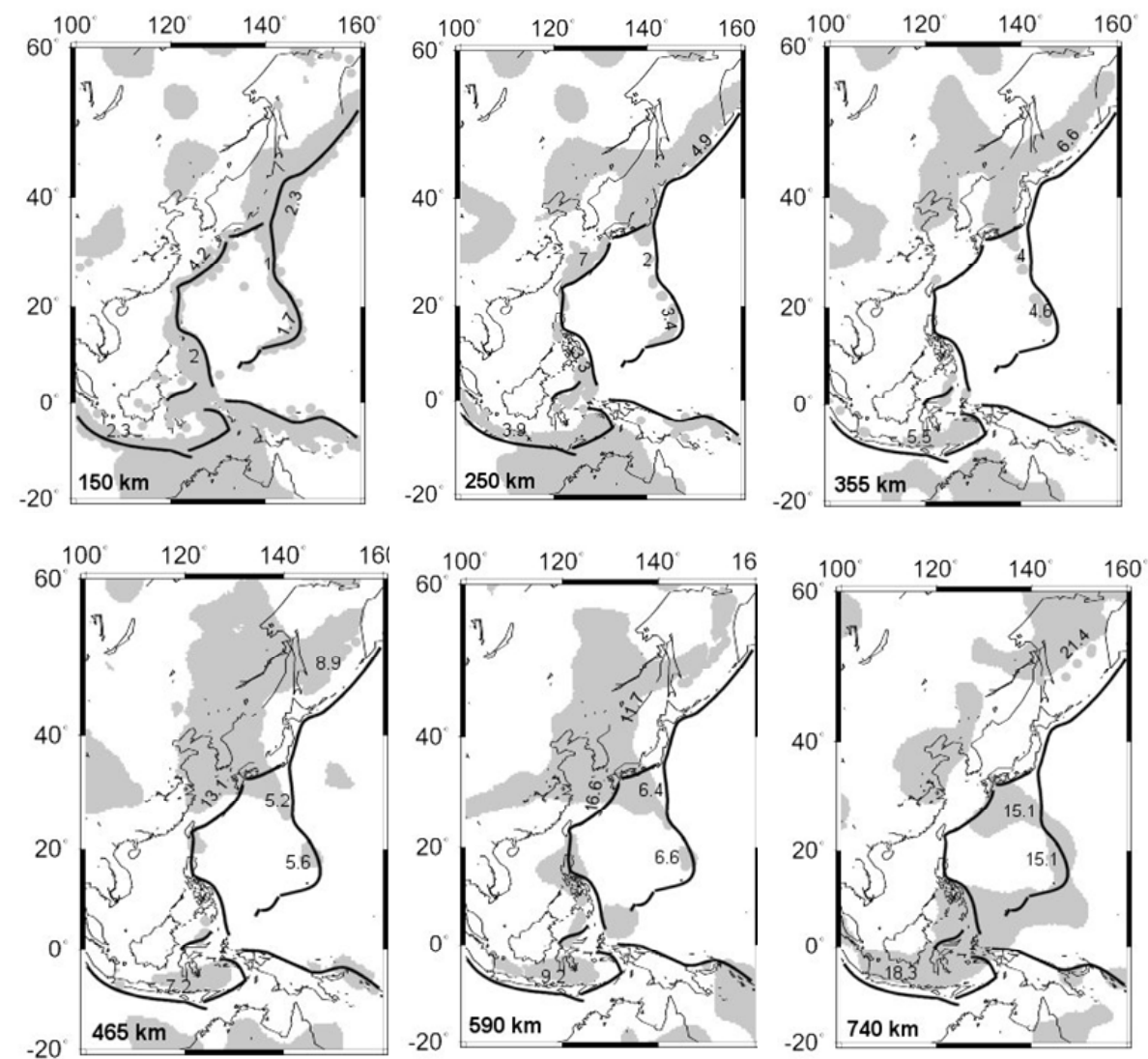

\section{Gambar 3. Peta sebaran lempeng tersubduksi (daerah terarsir abu-abu) untuk beberapa kedalaman lapisan dalam mantel yang diambil dari hasil tomografi gelombang seismic $P$ dan S (gambar modifikasi dari Handayani 2004, data dari Widiyantoro, 1997).}

\section{DISKUSI}

Hasil analisa tomografi (gambar 3) memperlihatkan sebaran lempeng tersubduksi di daerah Pasifik Barat. Sebaran lempeng yang cukup luas dan tebal berada di sebelah Barat kepulauan Jepang, dan dijumpai hampir di semua kedalaman lapisan. Demikian juga sebaran lempeng di bawah zona subduksi Izu-Bonin dan Mariana dijumpai hampir di semua kedalaman lapisan, namun relatif lebih sempit, kecuali pada kedalaman lapisan $740 \mathrm{~km}$ dimana sebaran lempeng tersebut relatif lebih luas.
Dari analisa tomografi ini, tampak adanya perbedaan karakter sebaran lempeng tersubduksi di Barat Jepang dengan yang ada di Izu-Bonin dan Mariana. Di sebelah barat Jepang, sebaran lempeng tersubduksi terhadap kedalaman cenderung melebar dan bergeser ke arah Barat menjauh dari posisi palung yang sekarang. Sebaliknya sebaran lempeng tersubduksi di bawah zona Izu-Bonin yang tampak pada semua kedalaman lapisan mempunyai pola yang sama dengan pola subduksi saat ini, dengan sudut penunjaman yang cukup besar hingga mendekati $90^{\circ}$. 
Bila mengacu pada teori rekonstruksi yang dikemukakan Hall (2002), dimana Lempeng Laut Filipina telah bermigrasi dan terotasi yang cukup cepat sejak Miosen (Gambar 2), maka diharapkan pola sebaran lempeng tersubduksi di Izu-Bonin akan mempunyai kemiripan dengan yang ada di sebelah Barat kepulauan Jepang (tahap migrasinya dijelaskan di Gambar 4). Kemiripan pola sebaran lempeng yang diharapkan adalah adanya jejak-jejak sebaran lempeng tersubduksi yang melebar ke arah Baratdaya pada setiap kedalaman lapisan. Hasil pemodelan tomografi daerah ini ternyata tidak menunjukkan adanya kemiripan pola sebaran tersebut. Atau dengan kata lain, kecil kemungkinannya bahwa lempeng tersubduksi Izu-Bonin pernah terotasi hingga $90^{\circ}$ dalam sejarah evolusinya.
Sebaran lempeng tersubduksi yang tampak dari pemodelan tomografi lebih sesuai dengan teori pergerakan Lempeng Laut Filipina yang sejak pembentukannya telah bergerak ke arah Utara dengan sedikit terotasi searah dengan jarum jam (Seno \& Maruyama, 1984; Hilde et al., 1977; Uyeda et al., 1972). Evolusi lempeng tersebut tampak pada Gambar 5 yang menguraikan pergerakan lempeng sejak pembentukan awal lempeng hingga kondisi lempeng saat ini.

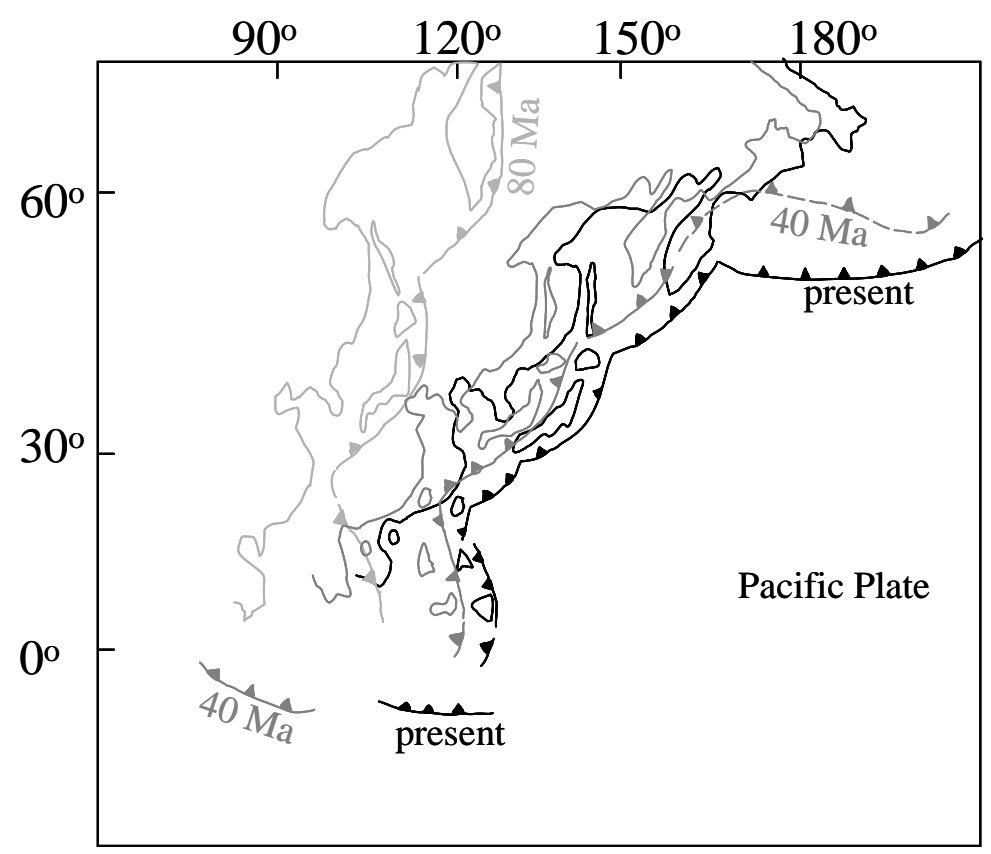

Gambar 4. Beberapa tahap migrasi zona subduksi sepanjang bagian barat dari Lempeng Pasifik (dimodifikasi dari Garfunkel et al., 1986). 


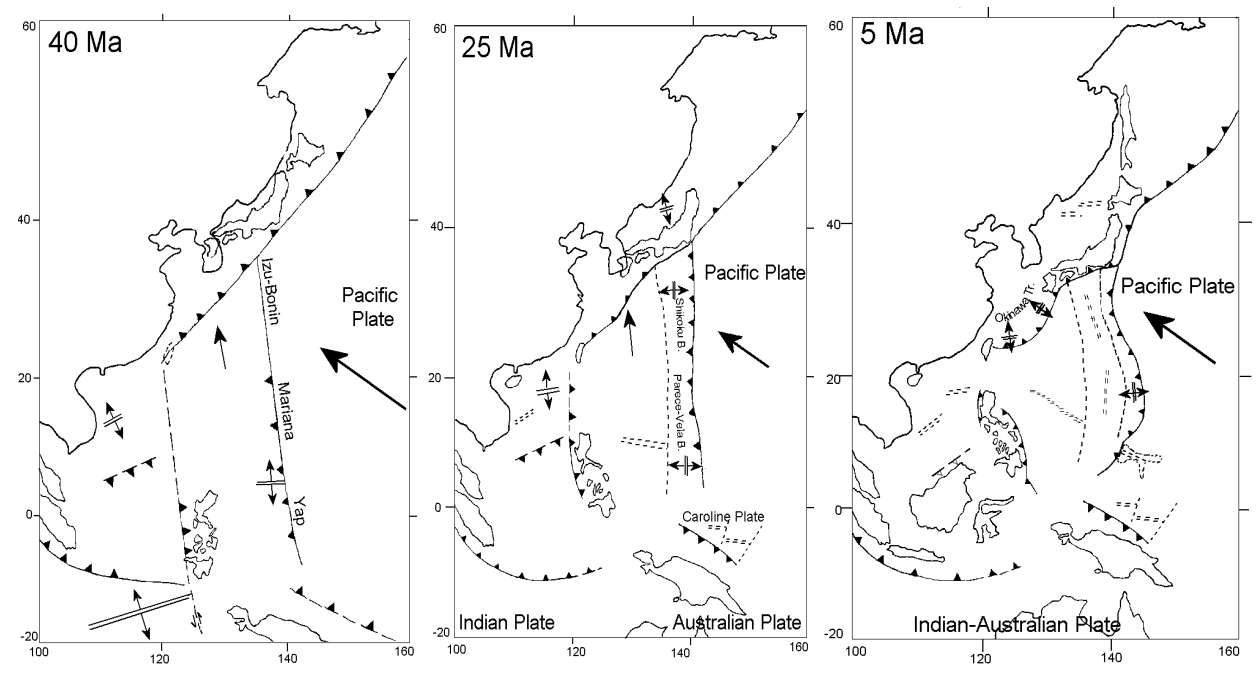

Gambar 5. Rekonstruksi Lempeng Laut Filipina

\section{KESIMPULAN}

Model tomografi dari gelombang seismik yang dapat menggambarkan penyebaran lempeng tersubduksi ternyata tidak menunjukkan bukti adanya rotasi Lempeng Laut Filipina sebesar hampir $90^{\circ}$ dalam waktu kurang lebih 50 juta tahun seperti yang diuraikan Hall (2002) dalam teori rekonstruksinya. Studi ini juga menunjukkan kemampuan pemodelan tomografi dalam analisa tektonik.

\section{UCAPAN TERIMAKASIH}

Terimakasih yang tak terhingga untuk Dr. Sri Widiyantoro yang telah mengijinkan saya untuk mengutak-utik model tomografinya. Juga terimakasih banyak untuk Ir. Kamtono, MSi. sebagai editor yang telah membantu menyempurnakan tulisan ini.

\section{REFERENSI}

Deschamps, A., 2001, Contribution à l'étude du Bassin Ouest Philippin, nouvelles donnees sur la bordure Ouest et la dorsale fossile. Ph.D. Dissertation, University of Montpellier 2.
Garfunkel, Z., Anderson, C.A., Schubert, G., 1986, Mantle circulation and the lateral migration of subducted slabs. Journal of Geophysical Research 91, 7201 - 7223.

Hall, R., 2002. Cenozoic geological and plate tectonic evolution of SE Asia and the SW Pacific: computer-based reconstructions, model and animations. Journal Asian Earth Science 20, 353-431.

Hall, R., Fuller, M., Ali, J.R., Anderson, C.D., 1995. The Philippine Sea Plate: Magnetism and Reconstructions. In: Taylor, B. and Natland, J. (eds.), Active Margins and Marginal Basin of the Western Pacific. Geophysical Monograph, vol. 88. American Geophysical Union, Washington, D.C., pp. 371-404.

Handayani, L., 2004. Seismic Tomography Constraints on Reconstructing the Philippine Sea Plate and Its Margin. Ph.D. Dissertation, Texas A\&M University, $133 \mathrm{pp}$.

Haston, R.B., Fuller, M., 1991. Paleomagnetic data from the Philippine Sea Plate and 
their tectonic significance. Journal of Geophysical Research 96, 6073 - 6098.

Hilde, T.W.C., Uyeda, S., Kroenke, L., 1977. Evolution of the Western Pacific and its margin. Tectonophysics 38, 145-165.

McCabe, R., Kikawa E., Cole J., Malicse, A.J., Baldauf, P.E., Yumul, J., Almasco, J., 1987. Paleomagnetic results from Luzon and the Central Philippines. Journal of Geophysical Research 92, 555-580.

Seno, T., Maruyama, S., 1984. Paleogeographic reconstruction and origin of the Philippine Sea. Tectonophysics 102, 53 84.
Smith, W., Sandwell, D.T., 1997. Global sea floor topography from satellite altimetry and ship depth soundings. Science 277, 1956-1962.

Uyeda, S. and Ben-Avraham, Z., 1972. Origin and development of the Philippine Sea. Nature Physical Science 240, 176-178.

Widiyantoro, S., van der Hilst, R.D., 1997. Mantle structure beneath Indonesia inferred from high resolution tomographic imaging. Geophysical Journal International 130, 167-182. 